\title{
A Study on the Effects of Pre-treatment in Dyeing Properties of Cotton Fabric and Impact on the Environment
}

\author{
Asaduzzaman ${ }^{1,2}$, Miah MR ${ }^{1,2}$, Hossain $F^{1}$, Li $\mathbf{X}^{1}$, Zakaria ${ }^{1}$ and Quan $\mathbf{H}^{1,2 *}$ \\ ${ }^{1}$ School of Chemistry and Chemical Engineering, Wuhan Textile University, Wuhan, Hubei, PR China \\ ${ }^{2}$ Wuhan Textile University Graduate (Color Root) Workstation, Songzi, 315600, Wuhan, Hubei, PR China
}

\begin{abstract}
Pre-treatment of cotton fabric prior to dyeing mainly involves a combined process consisting of scouring and peroxide bleaching. In this study main focus on to find out the major problem facing during dyeing of cotton fabrics. Pretreatment process has a greater impact on whiteness and dyeing properties of fabrics and also on environment. There are two process of pretreatment which is alkaline scouring and bleaching process and another is enzymatic scouring and bleaching process, between this two processes comparison and also observation its effects on whiteness of fabric, dyeing also impact on environment. It is also observe that the $3 \mathrm{gL}^{-1}$ hydrogen peroxide and 2 $\mathrm{gL}^{-1}$ sodium hydroxide give the good result on fabric whiteness with low environmental impact. Different pre-treated sample of cotton fabric dyed with reactive dye. The result obtain from dyed samples the combine pre-treatment by enzymatic scouring and bleaching gives good alternative of alkaline scouring bleaching process. Since it produce low BOD, COD and TOC impact on ecological factor. Furthermore it is also added advantages that it produces same whiteness and lower hydrolysation of dyestuff and good exhaustion.
\end{abstract}

Keywords: Cotton; Pretreatment; Enzymatic scouring; Bleaching; Hydrogen per oxide; Whiteness index; Dyeing

\section{Introduction}

Cotton is the oldest and the most important of the textile fibers. It has been used in the East and Middle East for thousands of years and was found in use in America when the continent was discovered. In fact, Cotton is called King Cotton, because of its versatility of its use and certain of its properties. Everyday cotton is the work's predominant textile fiber accounting 50 million tons per year and will maintain the leading position into the next century. We are using more cotton fabrics for our daily life survives in the world. For using of cotton fabric we have design and colored with different processes. Pretreatment is a process for prior fabric dyeing which involves scouring and bleaching. The object of scouring and bleaching is to produce white fabrics by destroying the colorings matter with the help of bleaching agents with minimum degradation of the fiber [1,2]. One of the important steps is scouring, in which the complete or partial non-cellulosic compounds found in cotton are removed, as well as impurities such as machinery and size lubricants $[3,4]$. The bleaching agents either oxidize or reduce the coloring matter which is washed out and whiteness thus obtained is permanent nature [5]. Now a days, highly alkaline chemicals, such as sodium hydroxide, are usually used for scouring in textile finished fabric production. These chemicals not only remove the impurities, but also attack the cellulose, leading to a reduction in strength, fabric weight loss $[6,7]$. So, the resulting waste water has a high COD (Chemical oxygen demand), BOD (biological oxygen demand), TDS (total dissolve solid) and higher content of salt. Now a day's textile producers have the possibility of applying a new, effective alternative to chemical scouring, with the enzyme and various other combined processes which are completely meet the requirements of scouring and bleaching $[8,9]$.

The aim of this research work was to investigate the influence of pre-treatment for textile dyeing properties and also effects on the environment. There is a process of pretreatment which includes scouring and bleaching process. We have tried to find out the environment friendly pretreatment process which is based on enzyme. Enzymes have lowest impact on the environment and good results for pre-treatment process. Reactive dyes form a covalent bond between the dye molecules and the $-\mathrm{OH}$ groups of cotton fiber in the dying process. This leads to favorable properties, such as wash fastness. Furthermore, unfix dye reacts with water to form hydrolyzed or oxy-dye that has lost its bonding capacity, and thus cannot be reused $[10,11]$. The dyes for this research were selected from Novacron series reactive dyes by Huntsman. These dyes had been developed for use in more environmentally friendly dyeing methods due to the fact that the dying process performs by the low salt. The colors of the bleach and dyed samples were determined using CIELAB 1976 color values and color different equations [12].

\section{Experimental}

\section{Materials}

A $100 \%$ cotton interlock knitted fabric $1 \times 1$ (200GSM) was used in this experiment. The interlock knitted fabric that we used as a substrate in this research was produced from combed cotton yarn on a special interlock circular knitting machine. Fabric was supplied by Concept Knitting Ltd, Tongi, Gazipur, Bangladesh.

\section{Chemicals and colorants}

Caustic soda flakes (98.5\%) and hydrogen peroxide (35\%) were collected from ASM chemical Ind. Ltd, Gazipur, Bangladesh, Detergent and wetting agent, Sequestering agent, leveling agent were supplied by Huntsman (BD) Ltd. Glacial acetic acid (99.99\%) and Soda ash (Sodium carbonate-99.2\%) were supplied by Trade Asia Int'l Pte Ltd.

*Corresponding author: Heng Quan, School of Chemistry and Chemical Engineering, Wuhan Textile University, Wuhan, Hubei, PR China, Tel: 86-27-59367541; E-mail: quanheng2002@163.com

Received October 26, 2016; Accepted October 28, 2016; Published October 31 2016

Citation: Asaduzzaman, Miah MR, Hossain F, Li X, Zakaria, et al. (2016) A Study on the Effects of Pre-treatment in Dyeing Properties of Cotton Fabric and Impact on the Environment. J Textile Sci Eng 6: 274. doi: 10.4172/2165-8064.1000274

Copyright: ( 2016 Asaduzzaman, et al. This is an open-access article distributed under the terms of the Creative Commons Attribution License, which permits unrestricted use, distribution, and reproduction in any medium, provided the original author and source are credited. 
Novacron Super Black G and Novacron Navy WB were supplied by Taha color Int'l Ltd.

\section{Equipment}

Laboratory scale knit fabric exhaust dyeing machine DATACOLOR AHIBA IR Pro were used for pre-treatment and dyeing of fabric. Spectrophotometer DATACOLOR 650 was used for measuring whiteness index of bleached fabric and also K/S value of dyed fabric.

\section{Recipe of processing}

The gray fabrics are pre-treated and dyed according to the following recipe which was presented in Tables 1 and 2 .

\section{Methods}

\section{Pre-treatment}

Interlock fabric has a technical face of plain fabric on both sides, but its smooth surface cannot be stretched out to reveal the reverse meshed loop wale's because the wale's on each side are exactly opposite to each other and are locked together [13]. The fabric was pretreated with the liquor ratio of 1:8 using two different procedures for simultaneous scouring and bleaching: modified alkali pre-treatment and enzymatic pre-treatment. The modified alkali pre-treatment and bleaching started at $50{ }^{\circ} \mathrm{C}$ in the presence of a $0.4 \%$ wetting agent (Invatex CRA) and $0.1 \%$ sequestering agent (Invatex CS). The bath was circulated for $5 \mathrm{~min}$, after which $6 \%$ sodium hydroxide and a peroxide stabilizer (Clarite CBB) were added. After a further 5 min circulation, $3 \mathrm{gL}^{-1}$ hydrogen peroxide was added, then the bath temperature was raised to $98{ }^{\circ} \mathrm{C}$ at a gradient $3{ }^{\circ} \mathrm{C} / \mathrm{min}$ and maintained for $60 \mathrm{~min}$. The enzymatic pre-treatment and bleaching started at $30^{\circ} \mathrm{C}$ with an addition of $1 \mathrm{ml} / \mathrm{l}$ of a commercial synergistic mixture of enzymes containing pectinases, hemicellulases and cellulases (Baylase EVO), and $1 \mathrm{ml} / \mathrm{l}$ of a bleaching stabilizer (Clarite $\mathrm{CBB}$ ). The bath was then heated to 98 ${ }^{\circ} \mathrm{C}$ at a gradient $3{ }^{\circ} \mathrm{C} / \mathrm{min}$. At $75^{\circ} \mathrm{C} 1 \mathrm{ml} / \mathrm{l}$ of the bleaching Stabilizer (Clarite CBB), $1 \mathrm{ml} / \mathrm{l}$ of a detergent and wetting agent (Invatex CRA), $2 \%$ (owf) sodium hydroxide and $5 \%$ hydrogen peroxide were added. At $98{ }^{\circ} \mathrm{C}$ the bleaching process continued for $60 \mathrm{~min}$. Both pre-treatment procedures were completed with neutralization and rinse.

\begin{tabular}{|c|c|c|}
\hline Process Chemicals & Function of the chemicals & Amount $\mathbf{~ g L}^{-1} \mathbf{)}$ \\
\hline Invatex CRA & Detergent \& wetting agent & 0.6 \\
\hline Invatex CS & Sequestering agent & 1 \\
\hline Clarite CBB & Peroxide Stabilizer & 0.5 \\
\hline Hydrogen peroxide (35\%) & Bleaching agent & 3 \\
\hline Caustic soda & Scouring agent & 2 \\
\hline Invatex PC & Peroxide killer & 0.3 \\
\hline Baylase EVO & Enzyme & $0.4 \%$ \\
\hline
\end{tabular}

Table 1: Pre-treatment Recipe.

\begin{tabular}{|c|c|c|}
\hline ChemicallDyes name & Function of the Chemicals/Dyes & Amount $\mathbf{~ g L}^{-1} \mathbf{)}$ \\
\hline Novacron Navy WB & Reactive dye & $2 \%$ \\
\hline Glauber salt & Electrolyte & 40 \\
\hline Soda Ash & Fixing agent & 14 \\
\hline Invadine LUN & Wetting agent & 0.5 \\
\hline Invatex CS & Sequestering agent & 0.5 \\
\hline Albatex DBC & Leveling agent & 0.5 \\
\hline Glacial Acetic acid & Neutralizer & 0.8 \\
\hline Eriopon OLS & Soaping agent & 1 \\
\hline & Table 2: Dyeing Recipe. & \\
\hline
\end{tabular}

\section{Measurement of weight loss \%}

Scouring of textile fiber loss a remarkable amount of weight (impurities like as oil, fats, wax, salts etc). The scouring effect, thus, can be evaluated based on this weight loss of fiber. Usually, it is calculated from Equation 1 the difference of un-scoured and scoured sample weight, measured in percentage of un-scoured weight of the sample.

$$
\text { Weight loss } \%=\frac{\boldsymbol{W}_{1}-\boldsymbol{W}_{2}}{\boldsymbol{W}_{1}} \times 100
$$

Where, $\mathrm{W}_{1}=$ Weight of the sample before scouring and, $\mathrm{W}_{2}=$ Weight of the sample after scouring

Absorbency test: The following tests were done to measure the absorbency of cotton fabric samples.

Sinking test: Absorbency may be assed in various ways, the most popular being the sinking time test [14]. Test specimens of $1 \mathrm{~cm} \mathrm{X} 1$ $\mathrm{cm}$ were cut at random and place on the surface of water. Slowly the fabric samples were wetted and entrapped air was removed. The time taken by the fabric samples to go inside water from floating state and sank in completely was noted down. The shorter the time taken by the specimen to sink in water completely, the greater is its absorbency.

Drop Test: The test was done according to the AATCC Test method 79 that measure a fabric's propensity to take up water, in which water drops are allowed to fall by gravity from a burette placed at a certain height from the fabric surface [14]. A drop of water is allowed to fall from a fixed height onto the taut surface of a test specimen. The time required for the specular reflection of the water drop to disappear is measured and recorded as wetting time.

Whiteness Index: The whiteness of each pretreated and chemically bleached sample was evaluated on the basis of the following CIE equation for illuminant D65 and $196410^{\circ}$ observer Equation 2:

$$
\boldsymbol{W}=\boldsymbol{Y}+800\left(\boldsymbol{x}_{\boldsymbol{n}}-\boldsymbol{x}\right)+1700\left(\boldsymbol{y}_{\boldsymbol{n}}-\boldsymbol{y}\right)
$$

Where $\mathrm{Y}$ is the tristimulus value of the sample; $\mathrm{x}$ and $\mathrm{y}$ are the chromaticity coordinates of the sample, $\mathrm{xn}$ and $\mathrm{yn}$ are the chromaticity coordinates for the perfect reflecting diffuser $(0.3138$ and 0.3310 , respectively).

Whiteness of fabric analyzed under spectrophotometer and weight loss were analyzed by taking weights of substrate before and after the bleaching process [15]. The CIE Whiteness Index value (CIE WI) was determined for the bleached fabric using AATCC test method. The whiteness was measured using a DATACOLOR 650, illuminants D-65 [16].

\section{Color Strength measurement}

The pre-treated and bleached samples were subsequently dyed with Novacron Super Black G and Novacron Navy WB reactive dyes in the DATACOLOR AHIBA IR laboratory apparatus at a liquor ratio of 1:10. The initial dyeing temperature was $30^{\circ} \mathrm{C}$ and the dyebath consisted of $0.5 \%$ sequestering agent (Invatex CS), $1 \%$ of a leveling agent (Albatex DBC) and electrolyte ( $40 \mathrm{~g} / \mathrm{l}$ Glauber Salt). Within 20 mins the dyebath was heated to $60^{\circ} \mathrm{C}$, after which the dye was added ( $2 \%$ o.w.f.). Then the dyebath was further running for 20 mins. Afterwards add to the dye bath of $14 \mathrm{~g} / \mathrm{l}$ of sodium carbonate $\left(\mathrm{Na}_{2} \mathrm{CO}_{3}\right)$. Finally run for the 45 min. After completion of run time rinsing the sample with cold and hot water, as well as neutralization with glacial acetic acid and soaping with $1 \mathrm{~g} / \mathrm{l}$ of a soaping agent (Eriopon OLS). Then the dyed sample was dried at $70^{\circ} \mathrm{C}$ and measure $\mathrm{K} / \mathrm{S}$ value. Color strength $\mathrm{K} / \mathrm{S}$ was measured on a datacolor -650 Spectrophotometer. These values are calculated using 
the following Equation 3 "KUBELKA-MUNK" equation:

$$
\frac{\boldsymbol{K}}{\boldsymbol{S}}=\frac{(1-\boldsymbol{R})^{2}}{2 \boldsymbol{R}}
$$

Where $\mathrm{K}$ is the absorption co-efficient, $\mathrm{R}$ is the reflectance of the dyed sample and $\mathrm{S}$ is the scattering co-efficient at the wavelength of maximum absorption. The pretreated and dyed samples of the cotton knitted fabric were colorimetrically evaluated using a spectrophotometer (Datacolor-650). The CIE equation was used to calculate the whiteness of the scoured and bleached samples, the CIELAB color values (lightness $\mathrm{L}^{*}$, red/green axis $\mathrm{a}^{*}$, yellow/blue axis $\mathrm{b}^{*}$, chroma $\mathrm{C}^{*}$, and hue $\left.\mathrm{h}\right)$, and the CIELAB color differences $\left(\Delta \mathrm{E}^{\star}\right)$ were determined for the dyed samples.

\section{Ecological impact measurement}

Ecological studies of the residual baths were performed by analyzing the Biochemical Oxygen Demand (BOD5), according to SIST EN 1899-2, the Chemical Oxygen Demand (COD) according to SIST ISO 6060, the Total Organic Carbon (TOC) according to SIST ISO 8245 , the biological degradation as a ratio of BOD5 and COD, and the spectral absorption coefficient SAC according to SIST EN ISO 7887.

\section{Result and Discussion}

\section{Effects of hydrogen peroxide on fabric whiteness and weight loss $\%$}

In order to reduce the time of bleaching process, increasing concentration of hydrogen peroxide and analyzes the effects on given substrate and compare with standard process. From the Figure 1 it was observe that, an increasing of hydrogen peroxide with temperature reducing the dwell time of the bleaching process. Whiteness increase with the increase of hydrogen peroxide, but at $3 \mathrm{gL}^{-1}$ we get the maximum whiteness of the fabrics. It is also observe that the whiteness of the alkaline bleach process is more than the enzymatic bleach process. Alkali is indispensable for activating hydrogen peroxide. Hydrogen peroxide in a weak acid or neutral medium has little or knows bleaching action. In an alkaline medium the following equilibrium Equation 4 is set up.

$$
\mathrm{H}_{2} \mathrm{O}_{2}+\mathrm{NaOH} \rightarrow \mathrm{Na}^{+}+\mathrm{HO}_{2}^{-}+\mathrm{H}_{2} \mathrm{O}
$$

Hydrogen peroxide is a powerful oxidizing agent that rapidly destroys the natural coloring matters present in cotton without undue oxidative damage to the fibers $[7,17]$. The effect of alkali, as seen from this equation is to shift the equilibrium to the right to increase the commemoration of per hydroxyl $\left(\mathrm{HO}_{2}^{-}\right)$ion, the bleaching agent and hence the bleaching action is intensified. However, peroxide bleached baths with alkali only are unstable and they require stabilizers of inorganic or organic nature.

It is also observed that from Figure 2 with the increase of hydrogen peroxide concentration weight loss percentage also increase $[18,19]$. In general, the time of bleaching is inversely proportional to the temperature of the bleach bath and weight loss of the fabric $[17,18]$.

\section{Effect of processing chemicals and methods on fabric} absorbency

Absorbency of a fabric can influence the uniformity and completeness of textile processing by the ability to take in water into fiber, yarn or fabric structure. Scouring imparts consistent and sufficient absorbency apart from enhancing the cleanliness of the material, bleaching further enhances the absorbability and imparts whiteness to the material. From Figure 3 revealed the average time taken by the samples to sink under their own weight. It is observe that the alkaline bleach fabric and enzymatic bleach fabric absorbency is very closer. For complete sinking of fabric it requires $42 \mathrm{sec}$ for alkaline bleach fabric and $48 \mathrm{sec}$ for enzymatic bleach fabric. Whereas gray fabrics were require more than $13 \mathrm{~min}$. So low sinking time indicates rapid wet ability resulted because of good pretreatment.

The fullness of bleaching as well as the suitability of a fabric for a particular use is dependent upon its ability and propensity to take up water. The absorbency of the samples assessed through drop test Figure 4 showed, there was tremendous improvement in the wettability of enzymatic bleach fabric. It is seen that enzymatic bleach fabric require $8 \mathrm{sec}$ whereas alkaline bleach fabric require $10 \mathrm{sec}$. But for the gray fabrics it requires more than $10 \mathrm{~min}$. So rapid disappear of water drop indicates the good pretreatment of fabric and it's also good prepare for dyeing.

\section{Effect of caustic soda concentration on the $\mathrm{H}_{2} \mathrm{O}_{2}$ bleached} fabric

The effect of increasing the amount of free caustic soda in bleach liquor containing peroxide stabilizer and $\mathrm{H}_{2} \mathrm{O}_{2}$ is shown in Figure 5.

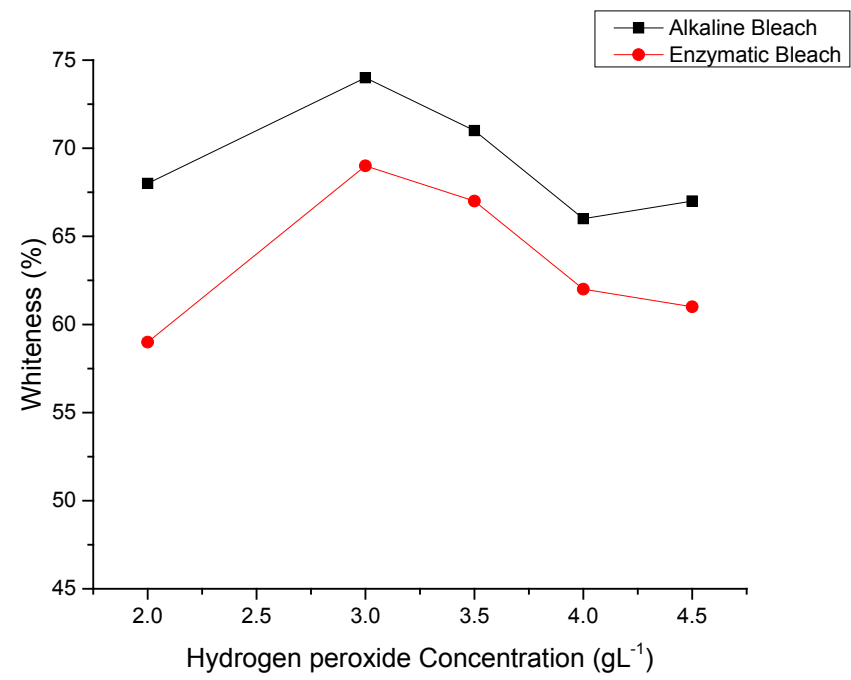

Figure 1: Effects of Hydrogen peroxide concentration on fabric whiteness.

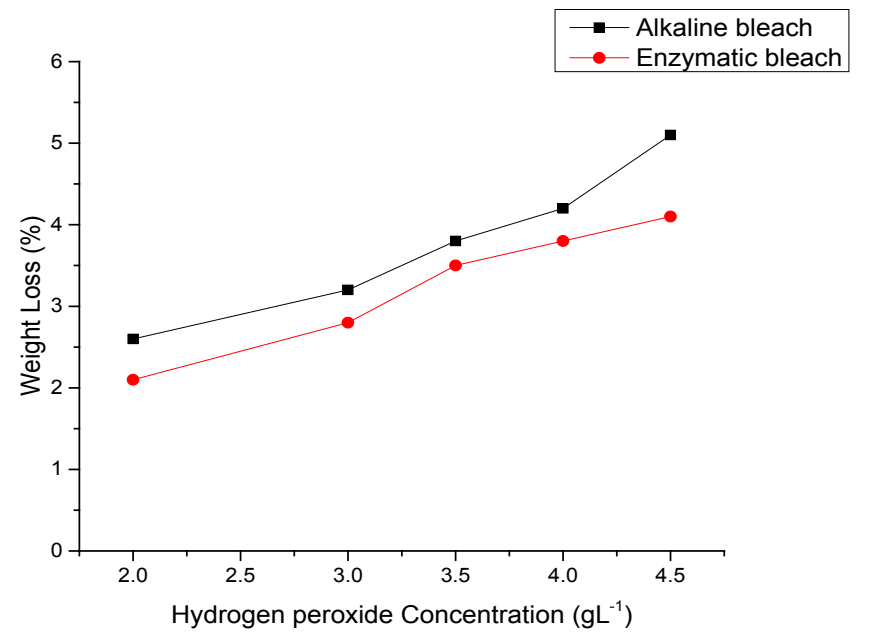

Figure 2: Effects of Hydrogen peroxide Concentration on weight loss $\%$. 
It is seen that the whiteness decreases with increasing free caustic concentration. At $2 \mathrm{gL}^{-1}$ caustic soda concentration we got the maximum whiteness of fabric. Alkaline bleach fabrics whiteness is more than that of enzymatic bleach fabric. Peroxide concentration in commercially accepTable bleaching in one stage bleaching is higher than that in the multistage process and peroxide requirement depends on the fabric type. Generally a whiteness of about $76 \%$ is obtained with $3 \mathrm{gL}^{-1}$ hydrogen per oxide.

\section{Colorimetrical evaluation}

Whiteness (CIE W) and lightness $\left(\mathrm{L}^{*}\right)$ of gray fabric and different pre-treated bleach fabrics are shown in Table 3 the results show that the lightness $L^{*}$ is higher for bleach fabric than gray fabric. But there is

No significant difference between alkaline bleach and enzymatic bleach sample. However the CIE whiteness obtain from alkaline pretreatment process (67.4) was higher than the enzymatic pre-treatment process $(62.6 \%)$, mainly caused by the differences the $b^{\star}$ axes.

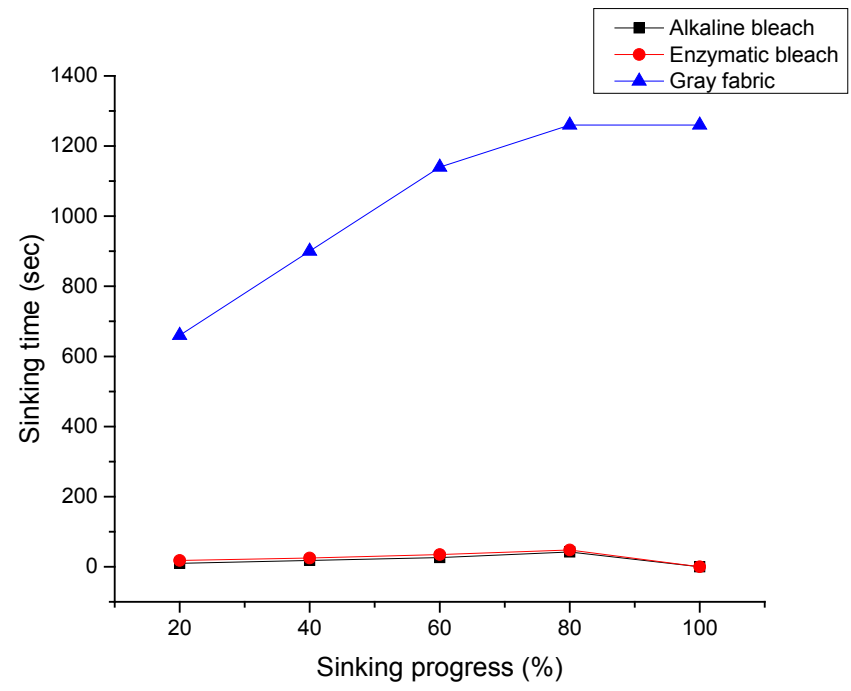

Figure 3: Sinking time of gray and differently pretreated fabrics.

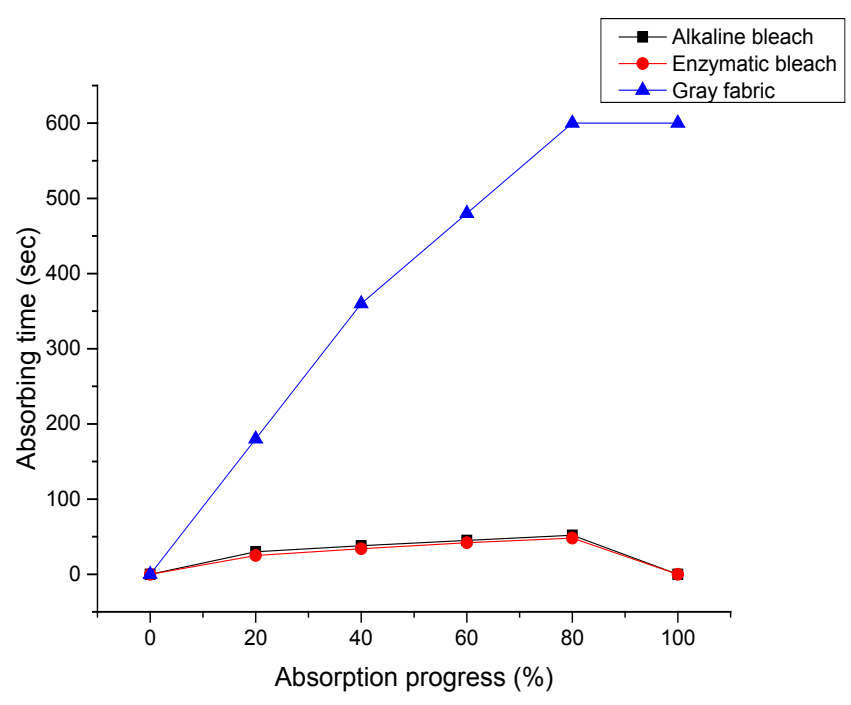

Figure 4: Drop test of gray and differently pretreated fabrics.

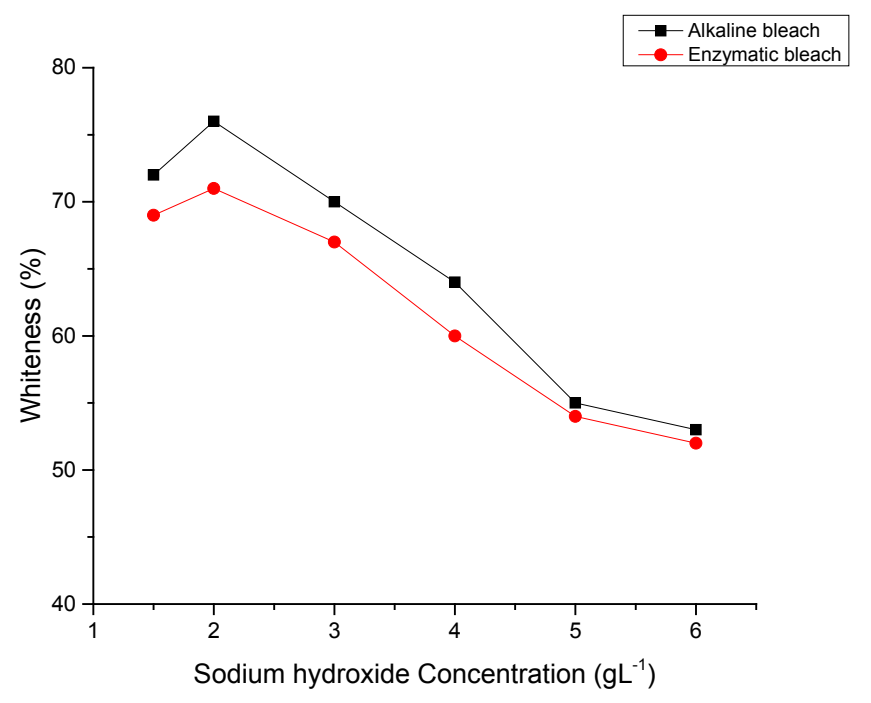

Figure 5: Effects of Caustic soda concentration on fabric whiteness.

\begin{tabular}{|c|c|c|}
\hline Samples & CIE W & L $^{*}$ \\
\hline Gray Fabric & 0 & 84.3 \\
\hline Alkaline Bleach & 67.4 & 92.5 \\
\hline Enzymatic Bleach & 62.6 & 92.1 \\
\hline
\end{tabular}

Table 3: Whiteness (CIE W) and Lightness $\left(L^{*}\right)$ of different samples.

Afterwards, the modified alkali pre-treatment and enzymatic treated cotton fabric were dyed using the two selected reactive dyes (Novacron Super Black G and Novacron Navy WB).

The dyed samples in all concentrations were colorimetrically evaluated by using CIELAB color system. CIELAB color values for $2 \%$ added dyestuffs are shown in Table 4. CIELAB color values of the dyed samples confirmed that the pre-treatment process had no important influence on the dyeing properties of the samples dyed using Novacron Super Black G and Novacron Navy WB dyes.

\section{Ecological impact of pretreatment}

The results of ecological analysis of the residual pretreatment baths are presented in Figure 6. The ecological analyses of the residual baths clearly showed the difference between the combined pre-treatment and bleaching processes performed. The TOC value of the residual bath after modified alkali pre-treatment was $20 \%$ higher than the TOC of the enzymatic pre-treatment waste-water. Since the TOC value gives the amount of total organic compounds present in wastewater, the lowest value of this parameter for the enzymatic pre-treatment is additional proof of its environmentally-friendly character. The COD and BOD5 values give the amount of oxygen needed for the oxidative and biological degradations of organic compounds in wastewater, respectively. The COD for the modified alkali pre-treatment wastewater was $41 \%$ and for BOD5 $31 \%$ higher than that for the enzymatic pretreatment wastewater. Both wastewaters of the pre-treatment were totally biologically degradable (for modified alkali pre-treatment it was 3.37, for enzymatic pre-treatment 3.43).

The residual baths analyzed were concentrated because the rinsing baths, which certainly lowered these values on an industrial scale, were not included; therefore, the relative comparison between the procedures is even more realistic. It should be noted that both pretreatment processes have a strong impact on environmental pollution, 
Citation: Asaduzzaman, Miah MR, Hossain F, Li X, Zakaria, et al. (2016) A Study on the Effects of Pre-treatment in Dyeing Properties of Cotton Fabric and Impact on the Environment. J Textile Sci Eng 6: 274. doi: 10.4172/2165-8064.1000274

Page 5 of 5

\begin{tabular}{|c|c|c|c|c|c|c|}
\hline Sam & Dyestuffs & $\mathrm{L}^{*}$ & $\mathbf{a}^{*}$ & $\mathbf{b}^{*}$ & $\mathrm{C}^{*}$ & H \\
\hline \multirow{2}{*}{$\begin{array}{l}\text { Alkaline bleach } \\
\text { and dyeing }\end{array}$} & vacron Navy WB & 24.1 & 62 & 9 & 6.9 & 7.9 \\
\hline & $\begin{array}{l}\text { Novacron Sup } \\
\text { Black G }\end{array}$ & 22.3 & -1 & -3.2 & 4.1 & 8 \\
\hline \multirow{2}{*}{$\begin{array}{l}\text { Enzymatic } \\
\text { bleach and } \\
\text { dyeing }\end{array}$} & Novacron Navy WB & & & & 16.9 & 248.0 \\
\hline & $\begin{array}{l}\text { Novacron Super } \\
\text { Black G }\end{array}$ & 25.2 & -2 & -4 & 3. & 1 \\
\hline
\end{tabular}

Table 4: CIELAB Color values of differently pre-treated and dyed samples.

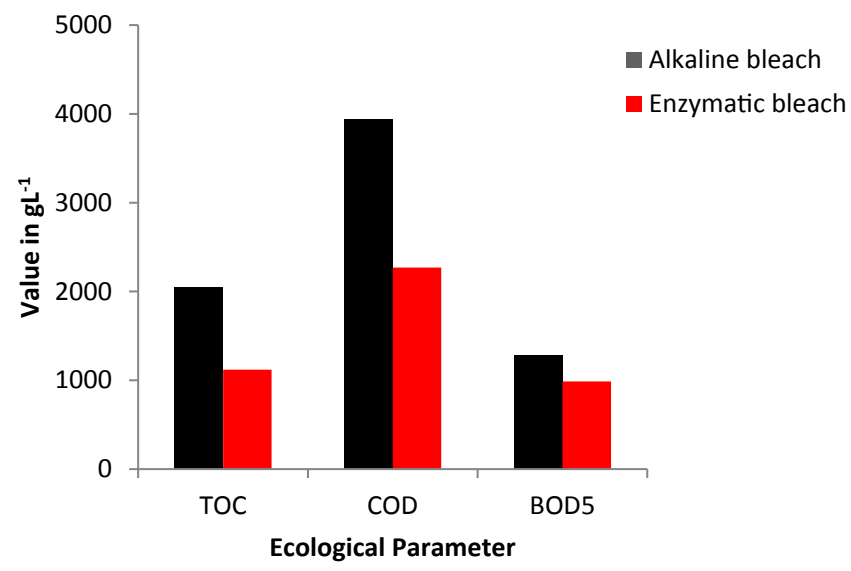

Figure 6: A comparisons of the ecological parameters of the waste water after applying combined pretreatment and bleaching process.

since all the ecological parameters exceeded the limits stated in Slovenian regulations $\left(\mathrm{TOC}=60 \mathrm{gL}^{-1}, \mathrm{COD}=200 \mathrm{gL}^{-1}\right.$ and $\mathrm{BOD} 5=30 \mathrm{gL}$ $\left.{ }^{1}\right)$ [20]. However, after combined single-bath scouring and bleaching, the volume of wastewater is significantly reduced. All the ecological parameters analyzed indicated that the degree of pollution of the residual baths was insignificant after enzymatic pre-treatment and bleaching.

\section{Conclusion}

It is observe that from results and discussion the combined bath pre-treatment processes performed, comprising scouring and bleaching, have a significant influence on the ecological parameters of the residual baths, but a minor influence on the whiteness color of the dyed cotton fabric using reactive dyes. At hydrogen peroxide conc. 3 $\mathrm{gL}^{-1}$ and sodium hydroxide $2 \mathrm{gL}^{-1}$ we have get good results with less environmental impacts. But cotton fabric pretreated with alkaline process and treated with enzymatic process almost similar when fabric dyed with Novacron navy WB, where as a greater difference $\left(\Delta \mathrm{E}^{\star}=4.1\right)$ was obtained with Novacron super black $G$ dyestuff, where combined alkaline process treated fabric produce a darker and less chromatic black color. Now a day's conventional or modified alkaline bleaching process produce more pollutant where as a good alternatives process of pre-treatment for cotton fabric treat with enzymes during bleaching which produce almost same fabric whiteness and depth of shade with lower environmental impact.

\section{Acknowledgements}

Author's would like to express sincere thanks to the Concept Knit Composite Ltd. Gazipur, Bangladesh for giving scope of doing this research work on their laboratory and providing the raw materials for this project.. Author's also express sincere appreciation to Md. Mizanur Rahman, General Manager, Concept dyeing Ltd. for his guidance and suggestions throughout the research work. This research was financially supported by the Wuhan Textile University postgraduate innovation team project. Author's would like to express deep appreciation to my supervisor Prof. Heng Quan, Vice Dean, Department of Chemistry and Chemical Engineering, Wuhan Textile University, China for his inspiring guidance, encouraging attitude and valuable suggestions for publishing this research work.

\section{References}

1. Shenai V (1991) Technology of Bleaching and Mercerizing. Sevak Publications (2ndedn) New Delhi, India.

2. Trotman E (1975) Dyeing and Chemical Technology of Fibers. London: Charles Griffin and Co. 617-618.

3. Madaras G, Shore J (1993) Batchwise dyeing of woven cellulosic fabrics Society of Dyers and Colourists.

4. Bae SH, Motomura H, Morita Z (1997) Diffusion/adsorption behaviour of reactive dyes in cellulose. Dyes and pigments 34: 321-340.

5. Shore J (1990) Colorants and auxiliaries.

6. Krässig HA (1993) Cellulose: structure, accessibility and reactivity. Gordon and Breach Science Publ.

7. Islam MR, Farhat FI (2016) Effect of Chemical Concentration on the Pretreatment Performance of Cotton Woven Fabric. IJCET.

8. Burget $L$ (1994) The Ecological Aspect of Cellulose Fibre Bleaching. Fibres and Textiles in Easten Europe.

9. Buschle-Diller G, Yang XD, Yamamoto Y (2001) Enzymatic bleaching of cotton fabric with glucose oxidase. Textile Research Journal 71: 388-394.

10. Karcher S, Kornmüller A, Jekel M (2002) Anion exchange resins for removal of reactive dyes from textile wastewaters. Water Research 36: 4717-4724.

11. Timofei S (2000) A review of QSAR for dye affinity for cellulose fibres. Dyes and Pigments 47: 5-16.

12. Schanda J (2007) Colorimetry: understanding the CIE system. John Wiley and Sons.

13. Spencer DJ (2001) Knitting technology: a comprehensive handbook and practical guide. CRC press.

14. Choudhury AKR (2006) Textile preparation and dyeing. Science publishers.

15. Jones B (1985) Effect of ozonation and UV irradiation on biorefractory organic solutes in oil shale retort water. Environmental progress 4: 252-258.

16. Xu C (2011) Review of Bleach Activators for environmentally efficient bleaching of textiles. Journal of Fiber Bioengineering and Informatics 4: 209-219.

17. Broadbent AD (2001) Basic principles of textile coloration. Society of Dyers and Colorists West Yorkshire, Canada.

18. Uddin M (2010) Determination of weight loss of knit fabrics in combined scouring-bleaching and enzymatic treatment. J Innov Dev Strategy 4: 18-21.

19. Sheth GN, Musale AA (2005) Single bath bio-scouring and bleaching of cellulosic yarn, Knitted and woven fabrics. Colourage 52: 49-52.

20. Golob V, Vinder A, Simonič M (2005) Efficiency of the coagulation/flocculation method for the treatment of dyebath effluents. Dyes and pigments 67: 93-97. 